\title{
The Strategies for the Production of Biodiesel through Eco-Friendly Microalgal Systems
}

\author{
V. Deepak, Aswathy Udayan, Nidhin Sreekumar
}

\begin{abstract}
The fast depleting energy sources and other environmental concerns, like carbon emissions, have led the scientific community on a race against time to find an ecofriendly, sustainable and renewable source of energy. Biofuels obtained from domestic used materials cannot practically satisfy the existing demand for an industrial fuel. Biodiesel is mono-alkyl esters of vegetable oils or animal fats. The major advantage of biodiesel is that it can be used directly into existing engines without any modifications. One of the potential sources for renewable biodiesel production which can effectively supply biodiesel for international and industrial demand is microalgae. Besides production of biofuels microalgae have been seen as a potential source for a number of areas including pharmaceuticals, nutrition and aquaculture. This review discusses on the different aspects, challenges and current scenario in the biodiesel production from microalgae. Cultivation of a high yielding marine microalgal strain in a very economical and well scrutinised open raceway pond could prove to be the key to future of energy sector. Various lipid enhancement methods and proposed culture methods are also discussed. On an industrial perspective, a well-engineered and continuously monitored open raceway pond for cultivation of marine micro algae seems to be a promising economically viable method for production of biofuel.
\end{abstract}

Keywords: Algal oil, Biodiesel, Lipid fuel, Microalgae, Open raceway pond reactor, Biofuel.

\section{INTRODUCTION}

$\mathrm{T}$ he dire need for an eco-friendly renewable source of energy arose with the realisation that the life force of human industrialisation, the fossil fuels, is fast depleting and with the need to reducing carbon emissions. Fossil fuels form a staggering $80 \%$ of all energy consumption at the present scenario. At the current rate of consumption the existing fossil fuel reserves will deplete in under 50 years [1]-[4]. The increase in the concentration of carbon dioxide has been attributed primarily to the use of fossil fuels and land use change, while agriculture contributes to methane and nitrous oxide [2]. Considerable reduction in the amount of carbon dioxide and other pollutants can be achieved by reducing the use of fossil fuels [3]. Being the primary energy producers, the focus naturally turned to liquid fuels derived from plant

Revised Manuscript Received on December 15, 2019.

* Correspondence Author

V. Deepak, Department of Biotechnology, School of Bio and Chemical Engineering, Kalasalingam Academy of Research and Education Krishnankoil, Tamilnadu, India. Email: v.deepak@klu.ac.in

Aswathy Udayan, Microbial Processing and Technology Division, CSIR

- National Institute for Interdisciplinary Science and Technology, Trivandrum, Kerala, India. Email: achuaswathyudayan@ niist.res.in

Nidhin Sreekumar*, Accubits Invent, Accubits Technologies Inc., India. Email: nidhins10@gmail.com biomass - biofuels - as a promising source of energy [3]-[6] The major advantage of liquid bio-fuels in comparison with other forms of renewable energy is that they could be applied in existing engines and other transport and allied infrastructures without any major changes [3], [6]. As far as liquid biofuels are concerned, algal biofuels is the most promising fuel [1], [7]. With the present research advances and culturing methods the mass culturing of microalgae for biodiesel production is becoming economical [2], [8]. To make it more economically viable, more research efforts are

required in the areas pertaining to the strain selection and mass culturing of microalgae. A discussion on the selection criteria of microalgal strains, culturing methods, different methods for lipid enhancements and culture condition optimisations has been detailed in this paper. The biodiesel production needs to be decentralised to meet the huge demands of the energy. The drawback of a decentralised system is that the strains should be hand-picked to match the culture conditions and the nutrient parameters. The selection of strain and culturing method is dependent upon each other and the location of culturing.

\section{ALGAL BIOFUELS AND ITS IMPORTANCE}

Biofuels are those fuels where the energy is obtained from biological carbon fixation [9]. Algal biofuels have a wide range of advantages over their predecessors like minimal land utilisation, less greenhouse gas emissions, rapid growth rates (certain species of algae can be harvested daily), a high per-acre yield ( 7 to 31 times greater than the next best crop palm oil), contains no sulphur, non-toxic, highly bio-degradable, and algae takes up $\mathrm{CO}_{2}$ as they grow, so they could be used as a viable carbon sequestration device, a sink for $\mathrm{CO}_{2}$ from power stations and other industrial plant that would otherwise cause serious atmospheric pollution [8], [10]-[15]. From the biodiesel perspective, the efficiency of energy production from a particular species is decided based on its lipid yield, resulting from conversion of solar energy into chemical energy [16].

Recent research on biodiesel is focused on oil extraction from algal species [17], [18]. Biofuel has 10-12\% more oxygen content than petroleum fuel $(4 \%)$ (Renewable and Alternative Energy Fact sheet) which form the major difference between them. The more the oxygen content the lesser is the external oxygen requirement for combustion.

Published By:

Blue Eyes Intelligence Engineering 


\section{The Strategies for the Production of Biodiesel through Eco-Friendly Microalgal Systems}

The initial and the vital step in biofuel production is the selection of suitable algae. Pulz and Gross (2004) observed that: "successful algal biotechnology mainly depends on choosing the right alga with relevant properties for specific culture conditions and products" [19]. The basic criteria of selection will vary from lipid productivity, growth rate, land consumption, to even economics based on the method of cultivation and output requirements [20], [21]. Around 3,000 species are isolated and screened in the Aquatic Species Programme [11], several of these are potential candidates for algal oil production in open ponds and can be used to consume carbon dioxide from coal-fired power stations, but a final verdict on a most suitable species is not provided. Marine microalgal species are reported to be particularly promising for lipid production by Rodolfi et al. [14]. On the outset, for a successful decentralised production system the selection should be tailored with respect to the conditions

\section{A. Classifications of Algae}

Algae are basic and simple structured, microscopic, photoautotrophic organisms with the major habitats as aquatic. Currently algae are getting much research attention as a probable source of biofuel owing to their high photosynthetic efficiency and lipid productivity.

Algae are classified based on its general size into microalgae and macroalgae. Some microalgal strains are reported to have the ability to double their mass multiple times per day. Macroalgae (or seaweeds) are generally considered as non- oleaginous (having very low lipid content) and are seldom considered as a biodiesel source. Macro algal cultivation is commonly carried out for extraction of natural sugars and other carbohydrates which could produce either biogas or alcohol-based fuels on fermentation [17].

Microalgae are broadly classified into four classes based on morphology: green algae, diatoms, golden algae and bluegreen algae [17]. There are about 100,000 species of Diatoms known and explored. Blue-green algae are prokaryotic, which is a distinguishing character when compared to other classes of microalgae. They are cyanobacteria species with oleaginous centres. Major production difficulty faced with blue-green algae is that the lipids are extracellular. Extracellular lipids and will attract predatory bacterial growth leading to contamination. Green algae also known as chlorophytes, are also abundant in nature. Till date approximately 8,000 species are explored and estimated to be in existence. Green algae have abundant chlorophyll a \& b while starch is the primary storage component. Green algae are usually referred to as "the evolutionary progenitors of higher plants" [11]. Golden- Brown Algae or chrysophytes, has similarities with diatoms considering the pigmentation and biochemical composition. Approximately 1,000 species are explored. Golden-Brown algae are found to exist predominantly in freshwater habitats. The major carbon storage in this class is reportedly lipids and chrysolaminarin.

Rapid growth and high productivity are exhibited by many microalgal species and many other species have been reported to accumulate $>70 \%$ of lipids in dry biomass on induction [11]. The use of marine microalgae in open ponds can

\section{ALGAL STRAIN SELECTION}

overcome the problem of the use of cultivatable land and marine species are much more productive and economic than fresh water algal species. From the above discussion it can be safely assumed that marine species of microalgae are better suited for biodiesel production.

\section{B. Microalgae-significance in Biofuel production}

Microalgae are a species of unicellular microscopic organisms that exist both as individuals and as clusters or chains and thrive well in marine and fresh water systems [22]. A vast variety of specialty products can be produced from a variety of microalgal species, that include enzymes, biopolymers, toxins, sterols, carotenoids, antioxidants, fatty acids, enzymes, polymers, peptides, toxins and sterols are only some of the entries [23]. Over 15000 well determined novel compounds have been already extracted and reported from algal biomass [22].

Microalgae are the most preferred microbes for the production of third generation biofuels. Microalgae can generate a variety of renewable biofuels. Even the algal biomass under anaerobic digestion produce methane [23] apart from the production of biodiesel from extracted oil [11] and biohydrogen production [24]. Carbon sequestration could be achieved by the large-scale cultivation of microalgae, so as to remediate the combustion exhaust of power plants [17], [18]. Oleaginous micro algae are reported to yield lipids as high as $142 \mathrm{mg} / \mathrm{L} /$ day [25].

There are many advantages of using microalgal biofuels. Being plant based microalgal biofuels are carbon neutral and are proven to be reducing Greenhouse Gases. It is reported that use of biofuel reduces greenhouse gas emissions up to 65 $\%$. Biodiesel made from cooking oil, in comparison with petroleum diesel is reported to produce $87 \%$ less greenhouse gas.

Algal biomass is reported to yield about 30 times more energy per acre than any other land-based crops like soybeans [11]. Oil produced in 1-ha of waste land converted to algae is reported to produce 10-100 times more yield than well-known oil crop [17]. The estimated oil yield varies from 20,000 to 80,0001 per acre, per year [18].

The local origin of biofuels decreases the nation's dependence upon foreign energy thereby preserving the foreign currency reserves of the nation [4]. Being produced locally, biofuel manufacturing plants generate employment to hundreds or thousands of workers, improving the local economics and living standards in rural areas. The use of biofuels will also increase the availability of other food crops, as microalgal farms are not utilising any cultivatable lands thereby inducing economic stimulation to the agriculture industry [26].

From the Table 1 it may be inferred that the microalgal arsenal is vast with a wide range of properties and climatic conditions. Further the lipid content in the wild strains needs to be closely studied for strain selection and should be enhanced by artificial methods for maximising the lipid productivity of the system.

Microalgae, at its exponential 
Table- I: Lipid composition of microalgae expressed on a dry matter basis

\begin{tabular}{|c|c|c|c|c|c|}
\hline Strain & Taxonomy & Media & $\begin{array}{c}\text { Mode of } \\
\text { cultivation }\end{array}$ & $\begin{array}{l}\text { Lipid \% } \\
\text { dry wt. }\end{array}$ & Ref \\
\hline Amphora sp. & Bacillariophyceae & Marine & Open RPR & 40 & [11] \\
\hline Anabaena cylindrica & Cyanobacteria & Fresh & Open RPR & $4-7$ & [27] \\
\hline $\begin{array}{l}\text { Botryococcus } \\
\text { braunii }\end{array}$ & Chlorophyta & Marine & Open RPR & $25.0-75.0$ & [28] \\
\hline $\begin{array}{l}\text { Chaetoceros } \\
\text { muelleri }\end{array}$ & Ochrophyta & Marine & Open RPR & 26 & [11] \\
\hline $\begin{array}{l}\text { Chlamydomonas } \\
\text { rheinhardii }\end{array}$ & Chlorophyta & Fresh & Open RPR & 21 & [28] \\
\hline $\begin{array}{l}\text { Chlorella } \\
\text { pyrenoidosa }\end{array}$ & Chlorophyta & Fresh & PBR & 2 & [27] \\
\hline Chlorella vulgaris & Chlorophyta & Fresh & Open RPR & $10-22$ & [27] \\
\hline Cyclotella cryptica & Ochrophyta & Marine & Open RPR & 24 & [11] \\
\hline Dunaliella bioculata & Prasinophyta & Saline & Open RPR & 8 & [11] \\
\hline Dunaliella salina & Prasinophyta & Saline & Open RPR & 35 & [29] \\
\hline $\begin{array}{l}\text { Dunaliella } \\
\text { tertiolecta }\end{array}$ & Prasinophyta & Saline & Open RPR & 11 & [29] \\
\hline Euglena gracilis & Euglenozoa & Fresh & Open RPR & $14-20$ & [28] \\
\hline Isochrysis galbana & Haptophyta & Marine & Open RPR & 22 & [27] \\
\hline Nannochloropsis sp. & Eustigmatophyta & Marine & Open RPR & 21 & [14] \\
\hline $\begin{array}{l}\text { Nannochloropsis } \\
\text { salina }\end{array}$ & Eustigmatophyta & Marine & Open RPR & 16 & [11] \\
\hline $\begin{array}{l}\text { Porphyridium } \\
\text { cruentum }\end{array}$ & Haptophyta & Marine & Open RPR & $9-14$ & [28] \\
\hline Prymnesium parvum & Haptophyta & Marine & PBR & $22-39$ & [28] \\
\hline $\begin{array}{l}\text { Scenedesmus } \\
\text { dimorphus }\end{array}$ & Chlorophyta & Fresh & PBR & $16-40$ & [28] \\
\hline $\begin{array}{l}\text { Scenedesmus } \\
\text { obliquus }\end{array}$ & Chlorophyta & Fresh & Open RPR & $12-14$ & [27] \\
\hline $\begin{array}{l}\text { Scenedesmus } \\
\text { quadricauda }\end{array}$ & Chlorophyta & Fresh & Open RPR & 1.9 & [28] \\
\hline Spirulina maxima & Cyanobacteria & Saline & PBR & $6-7$ & [30] \\
\hline Spirulina platensis & Cyanobacteria & Saline & PBR & $4-11$ & [27] \\
\hline Synechoccus sp. & Cyanobacteria & Marine & Open RPR & 11 & [11] \\
\hline $\begin{array}{l}\text { Tetraselmis } \\
\text { maculata }\end{array}$ & Chlorophyta & Marine & Open RPR & 22 & [11] \\
\hline
\end{tabular}

Table- II: Comparison of photobioreactor and raceway production methods [8]

\begin{tabular}{|l|l|l|}
\hline Parameters & $\begin{array}{l}\text { Photobioreacto } \\
\mathbf{r}\end{array}$ & Raceway ponds \\
\hline Annual Biomass production $(\mathrm{kg})$ & 100,000 & 100,000 \\
\hline Volumetric productivity $\left(\mathrm{kg} \mathrm{m}^{-3} \mathrm{~d}^{-1}\right)$ & 1.535 & 0.117 \\
\hline Biomass concentration $\left(\mathrm{kg} \mathrm{m}^{-3}\right)$ & 4.00 & 0.14 \\
\hline Dilution rate $\left(\mathrm{d}^{-1}\right)$ & 0.384 & 0.25 \\
\hline Area $\left(\mathrm{m}^{2}\right)$ & 5681 & 7828 \\
\hline Oil yield $\left(\mathrm{m}^{3} \mathrm{ha}^{-1}\right)$ & 136.9 & 99.4 \\
\hline Annual $\mathrm{CO}_{2}$ consumption $(\mathrm{kg})$ & 183,333 & 183,333 \\
\hline
\end{tabular}


phase have a very short biomass doubling time of about $3.5 \mathrm{~h}$ [8]. The oil content in a dry microalgae biomass can even be more than $80 \%$ by weight [23]. Lipid yield is a function of the algal growth rate and the oil-content of the biomass.

A biomass yield of $1.535 \mathrm{~kg} \mathrm{~m}^{-3}$ day $^{-1}$ has been reported for an optimised and well- engineered biodiesel production system carefully located in a tropical region [8]. On an average using $30 \%$ as the oil content in the dry biomass, the aforementioned rate of calculation, the yield per hectare of total land area would be approximately $123 \mathrm{~m}^{3}$ for almost the whole of the year. Another major inference from the Table 1 is that the wide range of microalgal species with good lipid productivity is available for marine environment. Also, seawater is of abundance in nature and does not interfere with any human primal requirements. As a result, the marine species is bound to be more economical.

\section{Marine microalgae}

It was reported that for obtaining $1 \mathrm{~kg}$ of dry biomass, tubular photobioreactors require $700 \mathrm{~kg}$ water whereas the raceaway systems require $4000 \mathrm{~kg}$ for alga cultures [31]. This will cause serious socio-economic impact on the locality of the mass culturing plant in terms of water and land availability. In the past, the potent candidature for algal oil production was limited to a certain species, majorly in fresh water conditions like Scenedesmus sp., Isochrysis sp., Chlorella sp. and Tetraselmis sp., have been reported [8], [10], [30]. With the exception of the marine genus Nannochloropsis, which was reported to be one of the best candidates for biodiesel production [14], very limited works have been carried out for biodiesel production in marine microalgae [32], [33]. With recent advances in phycology research, many higher lipid-yielding strains are being brought into the scenario. A total of 96 strains of marine microalgae, with an elevated biomass productivity (growth rate $\geq 0.55 \mathrm{~d}^{-1}$ ) and intracellular lipid content (42.5 to $45 \%$ dry wt. basis), were isolated from the coastal waters of Singapore, which are very suitable for biodiesel production [34]. The lipid productivity and biomass productivity of all algal species are influenced greatly by growth parameters like light, nutrient availability, temperature and dilution rate [35], [36]. The marine microalgal species is expected to be the promising biodiesel source in the near future.

\section{LIPID - THE PRECURSOR TO BIODIESEL PRODUCTION}

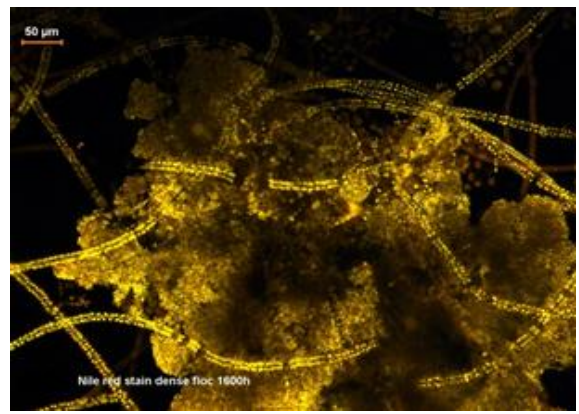

Fig. 1.Epi-flouroscent microscopic view of Nile-red stained microalgae showing lipid droplets (The golden glow signifies lipids).

Lipids are categorised into two based on its structure namely saturated and unsaturated. Examples of unsaturated fats are vegetable oils. The overall fuel properties of the biodiesel are dependent on the properties of the various individual fatty esters that comprise it [18]. Epi-flouroscent microscopic observations of nile-red stained algal samples can reveal lipid droplets as given in Figure 1. Alga produces poly-unsaturates (PUFA), which at higher levels tends to decrease the stability of biodiesel. To obtain a higher fuel quality, high proportions of saturated and mono-unsaturated fatty acids (MUFA) in the algal oil is considered optimal. Polymerization during combustion of monounsaturated fuels are reported to be substantially lesser than with PUFAderived fuel [11]. Algal biodiesel also have much lower melting points than MUFA or saturates; thus expected to have much better cold weather properties than any other bio- oils [37].

\section{A. Lipid accumulation}

Only a particular range of the incident solar radiation is actually useful for photosynthesis [7], [29].
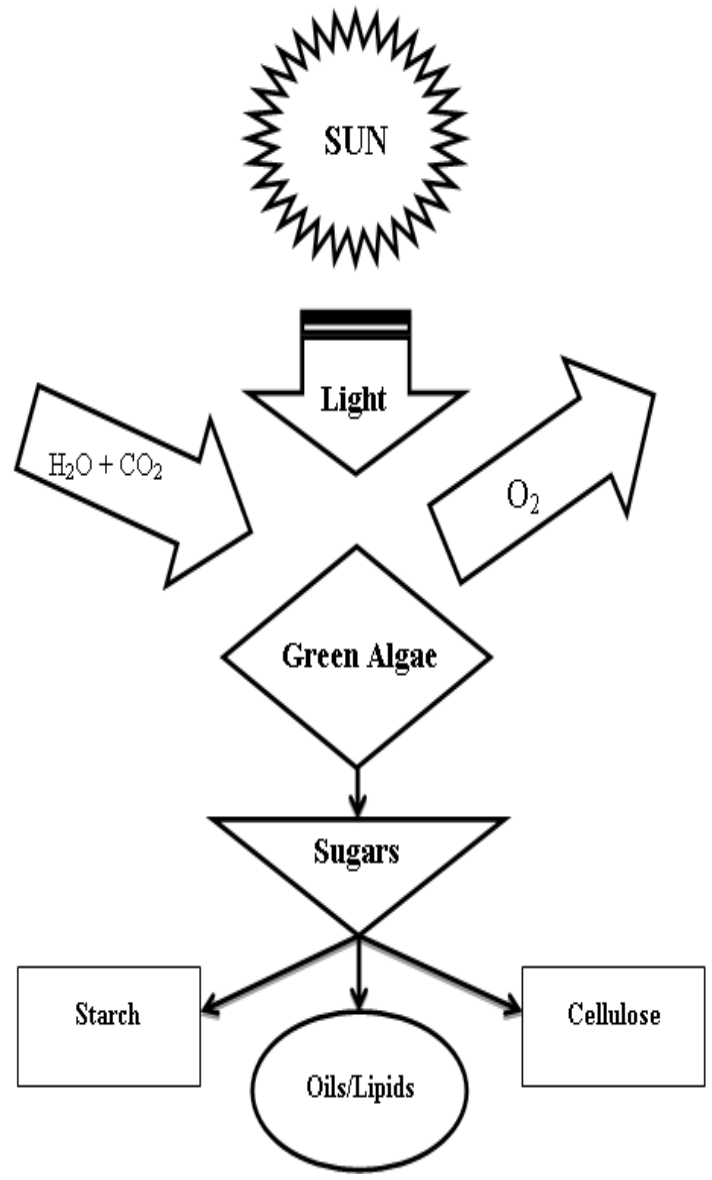

Fig. 2.Lipid accumulation pathway of microalgae.

Light in the wavelength range 400 to 700 nanometers, known as the Photosynthetically Active Radiation (PAR) is the part which is used for photosynthesis [29]. 


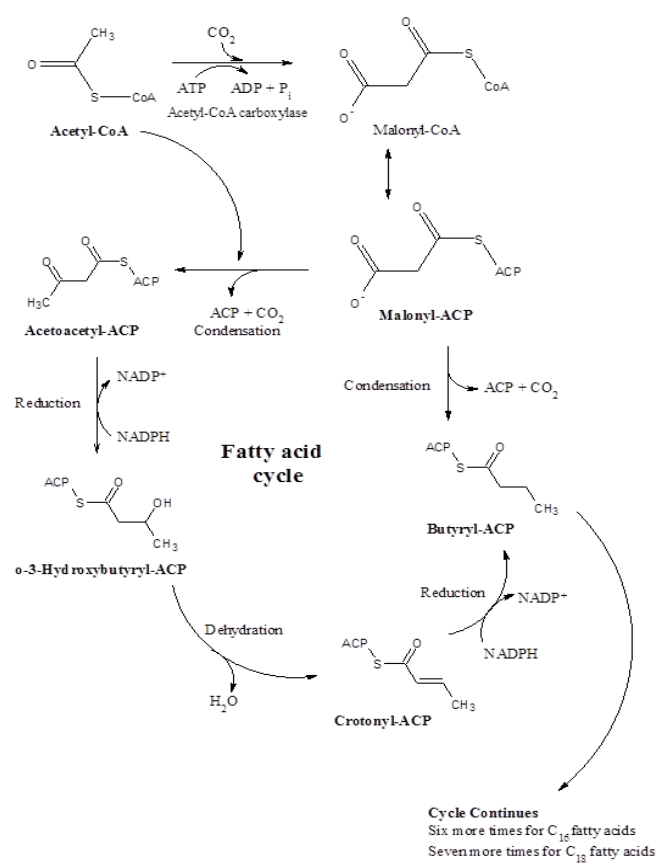

Fig. 3.Lipid production pathway of microalgae.

PAR is depended on the seasonal variations and dependent on the location and time of day. Figure 2 graphically describes the lipid production pathway in microalgal biomass. The measure of PAR is in terms of photon (quantum) flux. Quantum flux is the amount of photons in the radiant energy between $400 \mathrm{~nm}$ and $700 \mathrm{~nm}$. (One mole of photons is $6.0222 \times 10^{23}$ photons $\left(6.0222 \times 10^{23}\right.$ is Avogadro's Number). High incident light definitely promotes plant growth but can also cause photoinhibition at higher quantities thus keeping a close watch of PAR is essential to ensure plants are receiving sufficient light for this process [38].

Lipids are present in algae mostly as structural components of algae cells and organelles. Few among them are associated with proteins in chloroplasts. Rarely, under nitrogen depletion conditions when lipid accumulation is enhanced, lipids may be produced in free droplet form. Under stress conditions, such as nitrogen starvation, triacylglycerol (TAGs) are one of the main storage compounds present in many algal species. Figure 3 shows the biochemical pathway of lipid production in microalgae.

\section{B. Enhancement of lipid accumulation in cells}

Lipid accumulation of algal species can be enhanced by many methods like adjusting the culture conditions, genetically modifying the species or even by providing stressful conditions. Among these, genetic modifications will face an ethical issue and needs much more research into the feasibility and stability of the transgenic species. Adjusting culture parameters like light, nutrient availability, temperature and dilution rate have been reported to affect the biomass productivity and lipid accumulation in algal species [35], [36]. The effect of nitrogen, as a limiting constituent in the culture, on lipid accumulation has been well documented [36], [39]. Under stress conditions like as nitrogen stress etc., the growth of microalgae and the photosynthesis tend to decrease; hence the remaining energy is used for storage lipids synthesis [40].

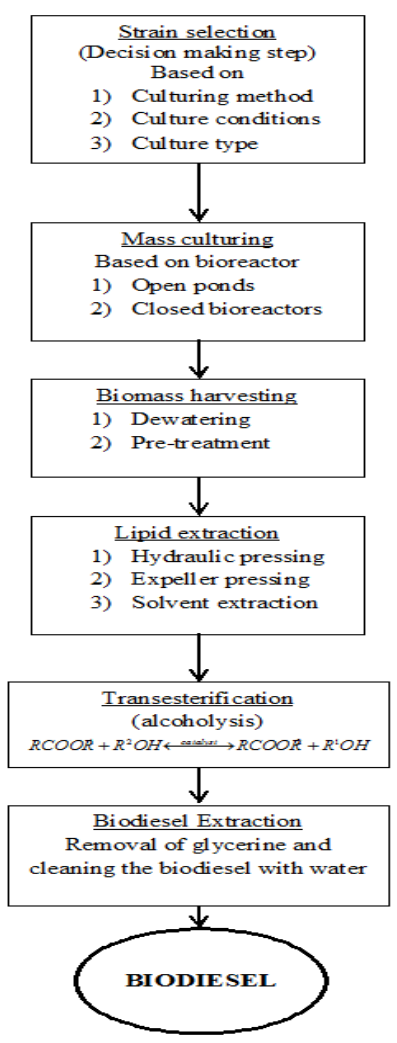

Fig. 4.General process flow diagram for biodiesel production from microalgal oil.

This method cannot be adopted for large scale cultivation as it will considerably reduce the biomass yield. A method, which allows the biomass to be grown at a higher pace along with higher lipid yield, was to be developed for the economically viable biodiesel production. An alternative two-stage cultivation process proposed which separates biomass production phase and lipid accumulation phase by providing individual conditions in each phase of culture. The initial of nutrient-rich conditions will ensure optimised microalgal growth (i.e. maximum biomass productivity). Whereas, in the second phase a nitrogen-limited condition will probe lipid accumulation [39], [41]. A general process flow chart is as given in the Figure 4.

\section{MICROALGAL CULTURING TECHNIQUES}

Mass culturing of microalgae could be carried out in open pond systems or closed systems. Alga culturing is the most promising, eco-friendly and economical process for the production of lipids. Mass culturing of algae requires huge quantities of nutrients and water, and significant energy inputs for the operation of the system [41]. The sources of water used for alga-culture can be of mediocre quality, like effluents from industrial processes, effluents from biological wastewater treatment or streams of other wastewater. Culture can either be mono or mixed based on the species present. In mono culturing a wild strain or a desired species is cultured in a specific culture media so as to grow it with no to minimal contamination. Whereas in a mixed culture, multiple strains of algae that are desired may be cultured with little chances of contamination.

Blue Eyes Intelligence Engineering 


\section{The Strategies for the Production of Biodiesel through Eco-Friendly Microalgal Systems}

Mixed culture requires minimal maintenance and is reported to be better yielding. Also, alga culture requires $\mathrm{CO}_{2}$ to be fed into the system, which can be collected from industrial exhaust. Any kind of culturing method should have nutrient feeding systems as well as monitoring and control systems for effective control and operation. The only economically viable and practical methods of mass production of microalgae are raceway ponds [31], [42] and tubular photobioreactors [31]. The open ponds, raceways, and lagoons are well established for the large-scale outdoor culturing of microalgae and cyanobacteria [28].

\section{A. Open pond systems}

One of the oldest and the simplest methods for mass cultivation of microalgae is open pond system. Figure 5 describes the different configurations of open pond systems. The most efficient and commonly used ponds are designed in a raceway configuration, in which a paddlewheel/propeller circulates and mixes the algal cells and nutrients. Ponds are $25-50 \mathrm{cms}$ in depth and made of concrete or are dug and coated with plastic wrap such that it would not come in contact with ground water. The ponds are made shallow so as to get a good exposure to sunlight at all times. After the completion of the circulation loop the broth is harvested upstream to the paddlewheel [17]. The continuous operation of paddlewheels ensures the prevention of sedimentation [8]. Open pond systems for large-scale outdoor culture of microalgae in raceways and lagoons are well documented and established [28].

In open raceways temperature control is achieved only by evaporation but water loss can be significant. Temperature fluctuates with time. Carbon dioxide utilisation is also much less efficient than photobioreactors because of atmospheric losses.
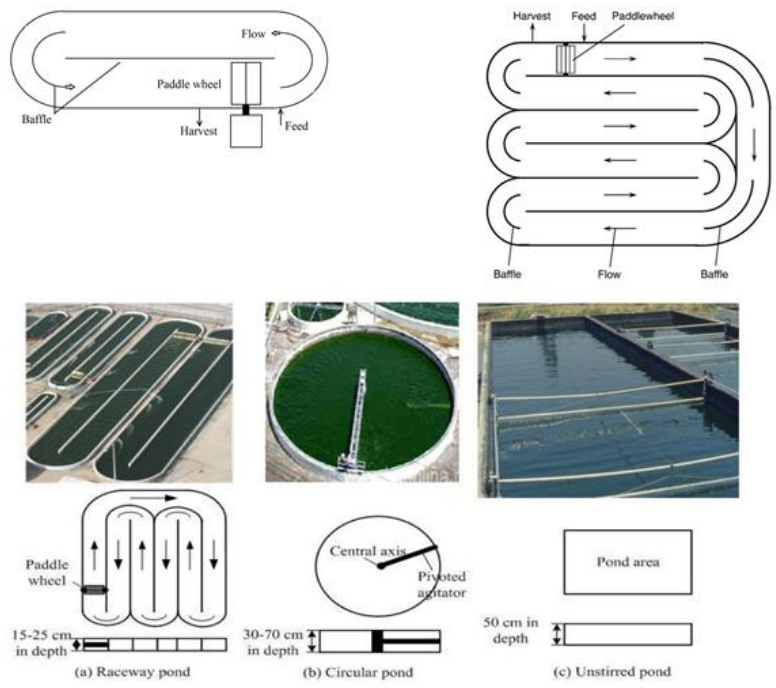

Fig. 5.Different modes for microalgal culturing [8].

Proper $\mathrm{pH}$ control and other physical parameters for introducing carbon dioxide (industrial exhaust/flue gas) into the ponds were reported to utilize more than $90 \%$ of injected $\mathrm{CO}_{2}$. The total productivity of algae will be negatively affected by contamination of unwanted microorganisms that feed on the desired ones [23]. The productivity of microalgae is measured in terms of biomass/lipid produced per day per unit of available surface area. The biomass concentration remains low because of poor mixing and low mass transfer rates [28]. Exhaustive research is required to overcome these shortcomings.

\section{B. Closed systems (Photobioreactors)}

Photobioreactors (PBR) are the most widely used type of closed systems in which algae can be cultivated. Technical and biological limitations of the open systems could be solved up to a limit by the use of PBR. These systems are usually illuminated by artificial light, solar light or by both [19]. Some commonly used variants of photobioreactors are stirred-tank, bubble column, airlift column, helical tubular, conical, type etc. [38].

A comparison based on 100 tonnes of biomass output is given in Table II. The various optimal combinations of concentration and biomass productivity that have been achieved are compared in Table II [8]. From the literature, the volumetric biomass productivity of photobioreactors is shown to be 13-times more compared to raceway ponds, the oil yield per hectare is also higher. Even though on comparison photobioreactors seems to be the better choice for large scale culturing open pond systems will have an upper edge based on cost considerations. After all, for an industrial fuel to be feasible cost and quantity of fuel is of prime importance. Apart from cost consideration another critical factor which influences the selection of culturing method is the efficiency based on light capture. The areal productivity in terms of light capture area is a significant decision factor in favour of open ponds. Open ponds have an edge over the closed photobioreactors in direct sunlight capture. From Table II the area requirement is marginal compared to the cost factor.

\section{Microalgae culture parameters}

The general conditions commonly used are listed in Table III.

Table- III: Generalized Set of Conditions for Culturing

\begin{tabular}{|c|c|c|}
\hline Parameters & Range & aptim \\
\hline Temperature $\left({ }^{\circ} \mathrm{C}\right)$ & $16-27$ & $18-24$ \\
\hline Salinity $\left(\mathrm{g} .1^{-1}\right)$ & $12-40$ & $20-24$ \\
\hline Light intensity (lux) & $\begin{array}{l}\text { 1,000-10,00 } \\
0 \quad \text { (depends } \\
\text { on volume } \\
\text { and density) }\end{array}$ & $\begin{array}{l}2,500 \\
5,000\end{array}$ \\
\hline $\begin{array}{l}\text { Photoperiod (light: } \\
\text { dark, hours) }\end{array}$ & & $\begin{array}{l}16: 8 \\
(\min ) \\
24: 0 \\
(\max )\end{array}$ \\
\hline $\mathrm{pH}$ & $7-9$ & $7^{8.2-8 .}$ \\
\hline
\end{tabular}

Algae, similar to all autotrophs thrive on photosynthesis for existence. The energy requirement for a good light penetration for a culture of about $10^{9}$ cells $/ \mathrm{mL}$ with an illuminated area of $1.0 \mathrm{~cm}^{2}$, is about $40 \mathrm{~mW} / \mathrm{cm}^{2}$ or more [43]. Natural or artificial lighting can be used according the availability and requirement. 
Photo-inhibition may result with strong light intensity (e.g. direct sun light, small container close to artificial light). Care must be taken to avoid overheating because of both artificial and natural illumination. Nutrient selection and addition should be based on the water analysis. Nutrients need to be added only to supplement the growth requirements. Under certain stress conditions, like light limited growth, and high nutrient availability, algal species have a tendency, much similar to other phytoplanktons, to take up nutrients in excess of immediate demands and to store up internal reserves which will be of use at a later period of time [44]. This concept can be utilised for improving the yield of microalgal species. The lack of any one of the important nutrients can limit the growth and productivity of algae in any given area.

Gas transfer rate is another major parameter to be considered while selecting or designing a reactor system. For a bioreactor system for algal growth $\mathrm{CO}_{2}$ needs to be dissolved into and $\mathrm{O}_{2}$ needs to be liberated, for which a good mass transfer coefficient needs to be maintained. Bubbling or sparging of $\mathrm{CO}_{2}$ as small bubbles through the system may increase the absorption efficiency and thus the $\mathrm{CO}_{2}$ uptake efficiency can be boosted up to $70 \%$ [31]. Aeration and mixing plays a major part in the any microbial cultures. Mixing or agitation is an absolute necessity so as to prevent the settling of algae in the reactor and to ensure light exposure and nutrient availability to all cells of the population equally. Mixing also improves the gas transfer rate in the system. The amount of $\mathrm{CO}_{2}$ captured by algal biomass varies with species; algal biomass [8].

Temperature control systems are a must for photobioreactor and other closed bioreactors. As far as open systems are concerned temperature is naturally controlled by evaporation. Temperature is a critical parameter in the case of external systems [45]. Over exposure to light or exposure to high intensity of light may result in death of the culture due to photoinhibition. The most applied and available method practically to cope with photo inhibition is to enhance the density of the microalgae to the point in where mutual shading relives the cells from receiving strong light.

The $\mathrm{pH}$ of the media is reported to play a vital role in the growth of the organism with slightly acidic $\mathrm{pH}$ showing diminished growth rates [21]. $\mathrm{CO}_{2}$ plays an important role in adjusting the $\mathrm{pH}$ levels in algal reactors. Higher dissolution of $\mathrm{CO}_{2}$ will reduce the $\mathrm{pH}$ of the system by generation of carbonic acid ions $\left(\mathrm{HCO}^{3-}\right)$. Higher growth rates in algae can be achieved by Carbon concentrating mechanism (CCM) which acts as an enhancer [46]. But higher concentrations will turn the growth media acidic and well outside the operating optima of the organisms. There are reports available which suggests that CCM is not induced at higher concentrations of $\mathrm{CO}_{2}$ [46]. An increase in $\mathrm{pH}$ can be observed with the growth of the culture, due to the formation of bicarbonates, and can be used as a measure of its activity.

The algal species and the specific cultivation conditions determine the molecular composition of the microalgae. In other words, the composition of the microalgae and its contents are not constant but widely varies. The changes in the on a general note about 1.8 tonne $\mathrm{CO}_{2}$ is required for 1tonne

composition of the microalgae is attributed to the variation in the environmental conditions like $\mathrm{pH}$, time of illumination, intensity of illumination, $\mathrm{CO}_{2}$ supply, temperature, nutrients and salts. This knowledge could be used to manipulate the products, which are generated.

\section{HARVESTING METHODS}

Microalgal biomass is simply a suspension of microorganisms that contains around $60 \%$ water. The greatest challenge to be encountered is of dewatering the biomass. For an efficient extraction of substantial amounts of natural oil, an efficient harvesting system is an absolute must [42]. Water can be removed in many ways like, settling, drying, screening etc. After the successful removal of water, the biomass is to be subjected to oil/lipid extraction. Different pre-treatment methods may be used prior to lipid extraction from microalgae. They are lyophilisation, inactivation of lipases, and addition of antioxidants. Antioxidants by nature have a tendency to improve the oxygen content in the lipid reserves there by enhancing the quality of biodiesel that is the eventual outcome. Unavailability of an effective and economical harvesting system is the major drawback in the microalgal biodiesel production system. A better dewatering and an improved harvesting system is the need of the hour and a major research gap.

\section{LIPID EXTRACTION FROM ALGAL BIOMASS}

Extraction of lipids from microalgal biomass can be done by different methods. They include solvent extraction, expeller pressing and hydraulic pressing [47]. Commonly solvent extraction is used. The Bligh and Dyer method is also often used for the extraction of total lipids from microalgae using chloroform-methanol (1:2) followed by an extraction with chloroform [48]. A comparison between Bligh and Dyer and Folch methods was done by Iverson et al. It was reported that for the determination of total lipid in marine tissue Bligh and dyer method gives a reduced effect for samples containing more than 2-10\% lipids [49]. The use of methyltert-butyl ether (MTBE) for solvent extraction instead the use of carcinogenic chloroform was proposed by Matyash et al. The upper phase of two-phase partitioning system has low density MTBE forms, which makes the collection process easy [50]. This method is found to yield the best in class recovery of almost all major lipid classes, even better than that of golden standards (Folch or Bligh and Dyer methods) [50]. For high accuracy and consistency, Ryckebosch et al. proposed the use of chloroform: methanol (1:1) ratio for the extraction of total lipid from small quantity of biological samples. Water is added for the removal of non-lipid substances from the extracted oil [51].

Many recent research works are available in literature on enhancing the solvent extraction using different methods. Extraction was reported to be enhanced by the use of microwave fragmentation technology [52], under supercritical ethanol conditions [53], hydro-thermal extraction [54] etc. More research must be carried out in this area also to tailor an optimised extraction system. 


\section{The Strategies for the Production of Biodiesel through Eco-Friendly Microalgal Systems}

\section{TRANSESTERIFICATION}

Biodiesel is mono-alkyl esters of vegetable oils or animal fats. The algal lipids are converted to biodiesel by transesterification. The commercially used transesterification method for biodiesel production utilises acid catalysts. The algal oil after extraction is treated with alcohol and catalyst. Recent studies show promising results by the use of biocatalysts [10]. Biodiesel production enzymatically in SC$\mathrm{CO}_{2}$ (supercritical $\mathrm{CO}_{2}$ ) is a recent finding which has much potential [54]. Effective transesterification can be achieved also by extra cellular and the intracellular lipases [10]. Lipase catalysed transesterification requires $1 / 3 \mathrm{rd}$ of the alcohol compared to other methods [10]. Recent advances have opened various bio-based catalysts for transesterification [55]. After the transesterification $\mathrm{pH}$ needs to be adjusted by the addition of alkali. Also, constant monitoring of free fatty acids (FFA) will provide the real time status of the process. An industrial fuel should have a neutral $\mathrm{pH}$ and the viscosity should be in the advisable ranges. To ensure quality of biodiesel, a properly optimised and chemically stable method is of prime importance.

\section{CONCLUSION}

Microalgal biofuel is a promising and economically viable option for our ever-growing energy demand. It is a renewable fuel source which has the ability of eliminate the use of fossil fuels. Research needs to be concentrated on maximising the lipid productivity of algal systems, by conditioning the algae, along with better economic feasibility. Improving the existing low-cost algal reactors for better productivity should be the major focus along with scrutinising the culture conditions. Considering the economics, open raceways are most likely to be used widely over high yielding, costlier photo bioreactors. Even though photo bioreactors provide a well-controlled environment, it is not suitable for large scale use. For large-scale production a well-engineered raceway is likely to be economically viable. Apart from the crucial choice of an economical culture method, the selection of a high yielding strain which is to be hand-picked according to the specific environmental conditions of the culture. The culture conditions and parameters are bound to vary according to the location of culturing. The choice of algal strain and culturing method are interdependent and independently depended on environmental conditions and operating parameters.

\section{REFERENCES}

1. L. Siwale et al., "Combustion and emission characteristics of n-butanol/diesel fuel blend in a turbo-charged compression ignition engine," Fuel, vol. 107, pp. 409-418, 2013.

2. S. Solomon, D. Qin, M. Manning, K. Averyt, and M. Marquis, Climate change 2007-the physical science basis: Working group I contribution to the fourth assessment report of the IPCC, vol. 4. Cambridge university press, 2007.

3. G. Tüccar and K. Aydın, "Evaluation of methyl ester of microalgae oi as fuel in a diesel engine," Fuel, vol. 112, pp. 203-207, 2013.

4. G. B. Leite, A. E. M. Abdelaziz, and P. C. Hallenbeck, "Algal biofuels: challenges and opportunities," Bioresour. Technol., vol. 145, pp 134-141, 2013.

5. N. Sreekumar, M. S. Giri Nandagopal, A. Vasudevan, R. Antony, and N. Selvaraju, "Marine microalgal culturing in open pond systems for biodiesel production - Critical parameters," J. Renew. Sustain. Energy, 2016.

6. C. D. Rakopoulos, A. M. Dimaratos, E. G. Giakoumis, and D. C Rakopoulos, "Study of turbocharged diesel engine operation, pollutan emissions and combustion noise radiation during starting with bio-diesel or n-butanol diesel fuel blends," Appl. Energy, vol. 88, no. 11, pp. 3905-3916, 2011.

7. N. Sreekumar, N. Selvaraju, C. Aneesh, and A. Haridas, "Fluorescence transients as a selection tool for marine microalgal consortia in a raceway pond reactor for biofuel production,” J. Sci. Ind. Res. (India). vol. 74, no. 11, pp. 645-650, 2015

8. Y. Chisti, "Biodiesel from microalgae," Biotechnol. Adv., vol. 25, no. 3, pp. 294-306, 2007

9. R. Oliver, D. Inderwildi, and A. King, "Quo vadis biofuels," Energy Env. Sci, vol. 2, p. 343e6, 2009.

10. V. K. Garlapati, R. Kant, A. Kumari, P. Mahapatra, P. Das, and R. Banerjee, "Lipase mediated transesterification of Simarouba glauca oil: a new feedstock for biodiesel production," Sustain. Chem. Process., vol. 1, no. 1, p. 11, 2013.

11. J. Sheehan, T. Dunahay, J. Benemann, and P. Roessler, "A look back at the US Department of Energy's aquatic species program: biodiesel from algae," vol. 328, 1998.

12. G. De Bhowmick, G. Subramanian, S. Mishra, and R. Sen, "Raceway pond cultivation of a marine microalga of Indian origin for biomass and lipid production: A case study," Algal Res., vol. 6, pp. 201-209, 2014.

13. D. Frumento, A. A. Casazza, S. Al Arni, and A. Converti, "Cultivation of Chlorella vulgaris in tubular photobioreactors: a lipid source for biodiesel production," Biochem. Eng. J., vol. 81, pp. 120-125, 2013.

14. L. Rodolfi et al., "Microalgae for oil: Strain selection, induction of lipid synthesis and outdoor mass cultivation in a low-cost photobioreactor," Biotechnol. Bioeng., vol. 102, no. 1, pp. 100-112, 2009.

15. O. N. Ciftci and F. Temelli, "Continuous biocatalytic conversion of the oil of corn distiller's dried grains with solubles to fatty acid methyl esters in supercritical carbon dioxide," Biomass and bioenergy, vol 54, pp. 140-146, 2013.

16. M. J. Griffiths and S. T. L. Harrison, "Lipid productivity as a key characteristic for choosing algal species for biodiesel production," $J$. Appl. Phycol., vol. 21, no. 5, pp. 493-507, 2009.

17. A. Demirbas and M. F. Demirbas, Algae energy: algae as a new source of biodiesel. Springer Science \& Business Media, 2010.

18. A. Demirbas and M. F. Demirbas, "Importance of algae oil as a source of biodiesel," Energy Convers. Manag., vol. 52, no. 1, pp. 163-170, 2011.

19. O. Pulz and W. Gross, "Valuable products from biotechnology of microalgae," Appl. Microbiol. Biotechnol., vol. 65, no. 6, pp. 635-648, 2004.

20. N. Sreekumar, A. J. Chennattussery, A. Mariya, and N. Selvaraju, "Anaerobic digester sludge as nutrient source for culturing of microalgae for economic biodiesel production," Int. J. Environ. Sci. Technol., vol. 15, no. 12, pp. 2607-2614, 2018.

21. N. Sreekumar, A. Haridas, G. S. Godwin, and N. Selvaraju, "Lipid enhancement in microalgae by temporal phase separation: Use of indigenous sources of nutrients," Chinese J. Chem. Eng., 2018.

22. S. Starckx, "A place in the sun-algae is the crop of the future, according to researchers in Geel, Flanders Today." 2012.

23. P. Spolaore, C. Joannis-Cassan, E. Duran, and A. Isambert, "Commercial applications of microalgae," J. Biosci. Bioeng., vol. 101, no. 2, pp. 87-96, 2006.

24. A. S. Fedorov, S. Kosourov, M. L. Ghirardi, and M. Seibert, "Continuous hydrogen photoproduction by Chlamydomonas reinhardtii," Appl. Biochem. Biotechnol., vol. 121, no. 1-3, pp 403-412, 2005.

25. T. M. Mata, A. A. Martins, and N. S. Caetano, "Microalgae for biodiesel production and other applications: a review," Renew. Sustain. energy Rev., vol. 14, no. 1, pp. 217-232, 2010.

26. A. Udayan, M. Arumugam, and A. Pandey, "Nutraceuticals from algae and cyanobacteria," in Algal Green Chemistry, Elsevier, 2017, pp. 65-89.

27. Y.-K. Lee, "Microalgal mass culture systems and methods: their limitation and potential," J. Appl. Phycol., vol. 13, no. 4, pp. 307-315, 2001.

28. E. W. Becker, "Photobioreactors: production systems for photo-trophic microorganisms," Microalga Biotechnol. Microbiol. Cambridge Univ. Press. Cambridge, UK, 1994.

29. M. Janssen, P. Slenders, J. Tramper, L. R. Mur, and R. Wijffels, "Photosynthetic efficiency of Dunaliella tertiolecta under short light/dark cycles," Enzyme Microb. Technol., vol. 29, no. 4-5, pp. 298-305, 2001. 
30. L. Gouveia and A. C. Oliveira, "Microalgae as a raw material for biofuels production," J. Ind. Microbiol. Biotechnol., vol. 36, no. 2, pp. 269-274, 2009.

31. F. G. Acién, J. M. Fernández-Sevilla, and E. Molina Grima, “A process to obtain biofuel from microalgae: Feasibility Analysis," in Fourth Congress of the International Society for Applied Phycology. Halifax. Canada, 2011, p. 41.

32. A. Udayan, S. Kathiresan, and M. Arumugam, "Kinetin and Gibberellic acid (GA3) act synergistically to produce high value polyunsaturated fatty acids in Nannochloropsis oceanica CASA CC201," Algal Res., vol. 32, pp. 182-192, 2018.

33. A. Udayan and M. Arumugam, "Selective enrichment of Eicosapentaenoic acid (20: 5n-3) in N. oceanica CASA CC201 by natural auxin supplementation," Bioresour. Technol., vol. 242, pp. 329-333, 2017.

34. T. T. Y. Doan, B. Sivaloganathan, and J. P. Obbard, "Screening of marine microalgae for biodiesel feedstock," Biomass and Bioenergy, vol. 35, no. 7, pp. 2534-2544, 2011.

35. G. S. Araujo, L. J. B. L. Matos, L. R. B. Gonçalves, F. A. N. Fernandes, and W. R. L. Farias, "Bioprospecting for oil producing microalgal strains: evaluation of oil and biomass production for ten microalgal strains," Bioresour. Technol., vol. 102, no. 8, pp. 5248-5250, 2011.

36. X. Huang, Z. Huang, W. Wen, and J. Yan, "Effects of nitrogen supplementation of the culture medium on the growth, total lipid content and fatty acid profiles of three microalgae (Tetraselmis subcordiformis, Nannochloropsis oculata and Pavlova viridis)," $J$ Appl. Phycol., vol. 25, no. 1, pp. 129-137, 2013.

37. A. Demirbas, "Production of biodiesel from algae oils," Energy Sources, Part A Recover. Util. Environ. Eff., vol. 31, no. 2, pp. $163-168,2008$.

38. O. Pulz and K. Scheibenbogen, "Photobioreactors: design and performance with respect to light energy input," in Bioprocess and algae reactor technology, apoptosis, Springer, 1998, pp. 123-152.

39. P. Bondioli et al., "Oil production by the marine microalgae Nannochloropsis sp. F\&M-M24 and Tetraselmis suecica F\&M-M33,' Bioresour. Technol., vol. 114, pp. 567-572, 2012.

40. S. Pal, A. Khossousi, C. Binns, S. Dhaliwal, and V. Ellis, "The effect of a fibre supplement compared to a healthy diet on body composition, lipids, glucose, insulin and other metabolic syndrome risk factors in overweight and obese individuals," Br. J. Nutr., vol. 105, no. 1, pp. 90-100, 2011.

41. S. Go, S.-J. Lee, G.-T. Jeong, and S.-K. Kim, "Factors affecting the growth and the oil accumulation of marine microalgae, Tetraselmis suecica," Bioprocess Biosyst. Eng., vol. 35, no. 1-2, pp. 145-150, 2012.

42. K. L. Terry and L. P. Raymond, "System design for the autotrophic production of microalgae," Enzyme Microb. Technol., vol. 7, no. 10, pp. $474-487,1985$

43. R. K. Mandalam and B. Palsson, "Elemental balancing of biomass and medium composition enhances growth capacity in high-density Chlorella vulgaris cultures," Biotechnol. Bioeng., vol. 59, no. 5, pp. 605-611, 1998.

44. M. F. Pedersen and J. Borum, "An annual nitrogen budget for a seagrass Zostera marina population,” Mar. Ecol. Ser., vol. 101, p. 169 , 1993.

45. M. Ras, J.-P. Steyer, and O. Bernard, "Temperature effect on microalgae: a crucial factor for outdoor production," Rev. Environ. Sci. bioltechnology, vol. 12, no. 2, pp. 153-164, 2013.

46. R. Ramanan, K. Kannan, A. Deshkar, R. Yadav, and T. Chakrabarti, "Enhanced algal $\mathrm{CO} 2$ sequestration through calcite deposition by Chlorella sp. and Spirulina platensis in a mini-raceway pond," Bioresour. Technol., vol. 101, no. 8, pp. 2616-2622, 2010.

47. Y. H. Hui, Bailey's Industrial Oil and Fat Products. V. 2 Edible Oil and Fat ProductsOils and Oil Seeds, no. L-0332. John Wiley and Sons, 1996.

48. E. G. Bligh and W. J. Dyer, "A rapid method of total lipid extraction and purification," Can. J. Biochem. Physiol., vol. 37, no. 8, pp. 911-917, 1959.

49. S. J. Iverson, S. L. C. Lang, and M. H. Cooper, "Comparison of the Bligh and Dyer and Folch methods for total lipid determination in a broad range of marine tissue," Lipids, vol. 36, no. 11, pp. 1283-1287, 2001.

50. V. Matyash, G. Liebisch, T. V Kurzchalia, A. Shevchenko, and D. Schwudke, "Lipid extraction by methyl-tert-butyl ether for high-throughput lipidomics," J. Lipid Res., vol. 49, no. 5, pp. 1137-1146, 2008.

51. E. Ryckebosch, K. Muylaert, and I. Foubert, "Optimization of an analytical procedure for extraction of lipids from microalgae," $J$. Am. Oil Chem. Soc., vol. 89, no. 2, pp. 189-198, 2012.
52. Y.-M. Dai, K.-T. Chen, and C.-C. Chen, "Study of the microwave lipid extraction from microalgae for biodiesel production," Chem. Eng. J., vol. 250, pp. 267-273, 2014.

53. H. K. Reddy et al., "Direct conversion of wet algae to crude biodiesel under supercritical ethanol conditions," Fuel, vol. 115, pp. 720-726, 2014.

54. H. Taher, S. Al-Zuhair, A. H. Al-Marzouqi, Y. Haik, and M. Farid, "Enzymatic biodiesel production of microalgae lipids under supercritical carbon dioxide: process optimization and integration," Biochem. Eng. J., vol. 90, pp. 103-113, 2014.

55. S. Chellappan, V. Nair, V. Sajith, and K. Aparna, "Synthesis, optimization and characterization of biochar based catalyst from sawdust for simultaneous esterification and transesterification," Chinese J. Chem. Eng., vol. 26, no. 12, pp. 2654-2663, 2018

\section{AUTHORS PROFILE}

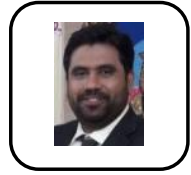

V. Deepak is working as Associate Professor in Biotechnology at Kalasalingam Academy of Research and Education, Krishnankoil, Tamil Nadu. He received his doctoral degree from KLU and later carried out post-doctoral Research in USA.

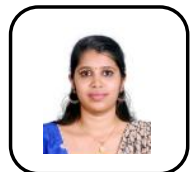

Aswathy Udayan is a DST-Inspire doctoral scholar at Microbial Processing and Technology Division, CSIR National Institute for Interdisciplinary Science and Technology, Trivandrum, Kerala, India She graduated from MG University with gold medal for her Master's degree in Microbiology.

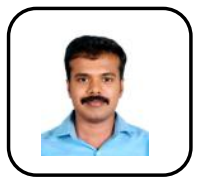

Nidhin Sreekumar is working as Chief Research Scientist at Accubits Technologies Inc. He was working as Associate Professor in Kalasalingam Academy of Research and Education, Krishnankoil, Tamil Nadu. He received his doctoral degree from NIT Calicut in 2018. 